prospective, real-world data on abatacept (ABA) retention in patients (pts) with RA

Objectives: To assess the retention rate and to identify prognostic factors of $A B A$ retention in the overall ACTION population and by treatment line over 2 yrs.

Methods: ACTION is a 2-yr, international, observational study of pts with RA who initiated IV ABA as first- or as second-/further-line biologic therapy in routine clinical practice. Biologic-naïve and biologic-failure pts were enrolled during three periods between May 2008 and December 2013. The primary endpoint was crude ABA retention rate over 2 yrs (Kaplan-Meier plot). Prognostic factors $(p \leq 0.2)$ from univariate analyses with no colinearity, clinically relevant variables and known risk factors were entered into a multivariate model; factors with $p \leq 0.1$ were retained by backward selection. EULAR response was compared by Fisher's exact test.

Results: In the ACTION cohort, 2350/2364 enrolled pts were evaluable for analysis; $673(28.6 \%)$ were biologic naïve and $1677(71.4 \%)$ had failed biologic treatment. Most biologic-failure pts $(56.6 \%)$ had previously received $\geq 2$ biologics. Some expected differences in baseline characteristics were observed between groups; mean (SD) RA duration was shorter (7.2 [8.2] vs 12.1 [9.1] yrs; $p<0.001)$, more pts had RA for $<2$ yrs $(35.7$ vs $9.0 \% ; \mathrm{p}<0.001)$ and fewer pts had radiographic erosions (58.2 vs $71.5 \% ; p<0.001)$ for biologic-naïve vs biologicfailure pts. At $\mathrm{Yr} 2$, the overall retention rate was $47.9 \%(95 \% \mathrm{Cl} 45.7,50.0)$. The retention rate was higher in biologic-naïve vs biologic-failure pts 54.5 vs $45.2 \% ; p<0.001$ ) and in pts with 1 vs $\geq 2$ previous biologics (Fig). Reasons for discontinuation were comparable between groups; main reasons were lack of efficacy $(61.4$ vs $67.7 \%)$ and safety (21.3 vs $21.2 \%)$. RF and anti-citrullinated protein antibody (ACPA) seropositivity were prognostic factors for higher retention in biologic-naĩve $(p=0.030)$ and biologic-failure pts $(p=0.028)$; other positively impacting factors were diabetes mellitus ( $\mathrm{p}=0.044$; biologic naïve); geographic location $(p<0.001$; biologic naïve) and ABA combination therapy $(p<0.001$; biologic failure). Only Pt Global Assessment ( $p=0.009$; biologic failure) predicted lower retention. Among pts continuing $A B A$, a greater proportion of biologic-naïve vs biologic-failure pts had a good/moderate EULAR response (90.7 vs $81.6 \%$; $\mathrm{p}=0.005)$ and RF/ACPA seropositivity was associated with a better response $(p=0.002)$. There were no new safety signals.

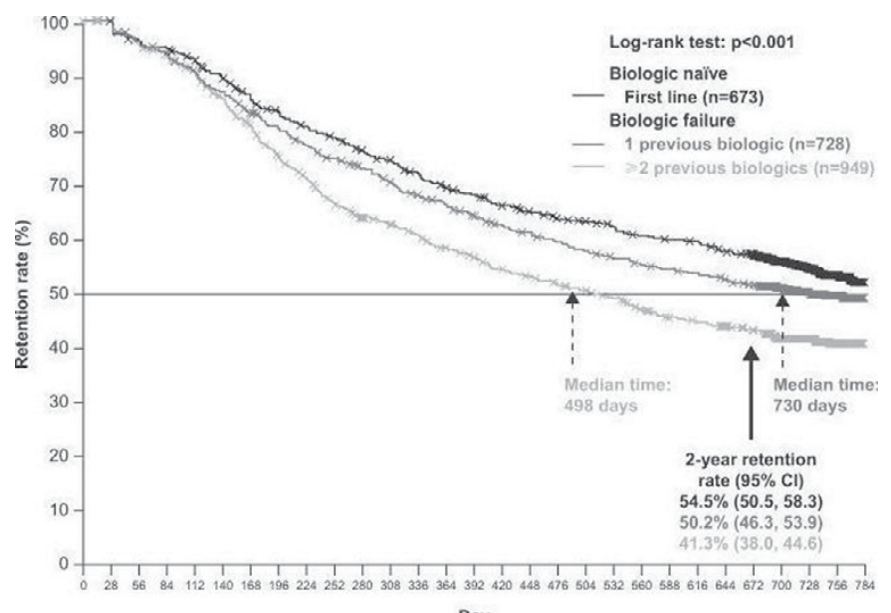

Day

Conclusions: In this first prospective, international, non-interventional research evaluating the long-term IV abatacept retention, RF and ACPA seropositivity were predictors of 2-yr higher retention and better outcomes. Higher retention rates may be achievable with earlier vs later initiation of abatacept treatment, consistent with prior findings from a pooled analysis of EU and Canadian registries. ${ }^{1}$

References:

[1] lannone F et al. Clin Rheumatol (2016): doi:10.1007/s10067-016-3505-5. Disclosure of Interest: R. Alten Grant/research support from: Bristol-Myers Squibb, Speakers bureau: Bristol-Myers Squibb, H.-M. Lorenz Consultant for: AbbVie, Bristol-Myers Squibb, Roche-Chugai, UCB, MSD, GSK, SOBI, Medac, Novartis, Janssen-Cilag, AstraZeneca, Pfizer, Actelion, X. Mariette Grant/research support from: Biogen, Pfizer, UCB, Consultant for: Bristol-Myers Squibb, LFB, Pfizer, GSK, UCB, H. Nüßlein Consultant for: AbbVie, Bristol-Myers Squibb, Celgene, Janssen, Lilly, MSD, Novartis, Pfizer, Roche, Speakers bureau: AbbVie, Bristol-Myers Squibb, Celgene, Janssen, Lilly, MSD, Novartis, Pfizer, Roche, M. Galeazzi: None declared, F. Navarro Grant/research support from: Pfizer, MSD, AbbVie, Bristol-Myers Squibb, Roche, Consultant for: Pfizer, MSD, Roche, UCB, AbbVie, Bristol-Myers Squibb, Jansen, Lilly, Speakers bureau: Pfizer, MSD, Roche, UCB, AbbVie, Bristol-Myers Squibb, M. Chartier Employee of: Bristol-Myers Squibb, Y. Elbez: None declared, C. Rauch Shareholder of: BristolMyers Squibb, Employee of: Bristol-Myers Squibb, M. Le Bars Shareholder of: Bristol-Myers Squibb, Employee of: Bristol-Myers Squibb

DOI: 10.1136/annrheumdis-2017-eular.1375

\section{FRI0246 IMPROVEMENTS IN HEALTH-RELATED QUALITY OF LIFE WITH SIRUKUMAB ARE STATISTICALLY SIGNIFICANT, CLINICALLY MEANINGFUL, AND MEET OR EXCEED NORMATIVE VALUES IN RHEUMATOID ARTHRITIS PATIENTS WITH INADEQUATE RESPONSE TO DISEASE-MODIFYING ANTIRHEUMATIC DRUGS: POST HOC ANALYSES OF A PHASE 3 TRIAL}

V. Strand ${ }^{1}, \mathrm{~K}$. McQuarrie $^{2}, \mathrm{~N} . \mathrm{Li}^{2}$, R. Ganguly ${ }^{3}$. ${ }^{1}$ Stanford University, Palo Alto, $C A ;{ }^{2}$ Janssen Research \& Development, LLC, Spring House, PA;

${ }^{3}$ GlaxoSmithKline, Collegeville, PA, United States

Background: Rheumatoid arthritis (RA) is associated with impaired health-related quality of life (HRQoL). Sirukumab (SIR) is an anti-interleukin-6 (IL-6) monoclonal antibody.

Objectives: These post hoc analyses evaluated improvements in HRQoL compared with an age/gender-matched normative population in a phase 3 randomized, controlled trial of SIR in RA pts with inadequate response to conventional disease-modifying antirheumatic drugs (DMARD-IR; SIRROUNDD).

Methods: 1670 pts received SIR 50mg every 4 weeks (q4w), SIR 100mg every 2 weeks (q2w), or placebo (pbo) q2w. Health-related physical/emotional well-being was measured at baseline $(\mathrm{BL})$ and Wk 24 by the 36-item Short Form Questionnaire (SF-36), fatigue by Functional Assessment of Chronic Illness Therapy (FACIT)-Fatigue (FACIT-F), and physical function by Health Assessment Questionnaire-Disability Index (HAQ-DI).

Results: SF-36 physical and mental component summary (PCS and MCS) mean scores at BL were comparable for pbo, SIR $50 \mathrm{mg} \mathrm{q4w}$ and $100 \mathrm{mg}$ q2w (PCS: 33.8, 34.2, and 33.5; MCS: 40.5, 40.5, and 41.8) and indicative of substantial impairment. At Wk 24, treatment with SIR $50 \mathrm{mg} \mathrm{q} 4 \mathrm{w}$ and $100 \mathrm{mg}$ q2w resulted in significantly greater mean improvements from BL vs pbo in SF-36 PCS (5.4 and 5.9 vs 2.3 ) and MCS (4.9 and 4.2 vs 2.9 ) scores (all $P<0.001$ ), exceeding the minimum clinically important difference (MCID) of 2.5. Least squares mean changes in all SF-36 domain raw scores were significantly greater with both doses of SIR than pbo at Wk 24 and all >MCID of 5.0 (Table; Figure). Substantial proportions of pts treated with SIR $50 \mathrm{mg}$ q4w or $100 \mathrm{mg}$ q2w reported scores $\geq$ normative values in SF-36 domains at Wk 24 (ranges: $20-33 \%$ and $21-36 \%$ ) vs pbo (range: 10-28\%). For pbo, SIR 50mg q4w, and SIR 100mg q2w, BL FACIT-F scores were 27.2, 27.1, and 27.5. Significantly greater proportions of pts reported clinically meaningful improvements in FACIT-F $(M C I D=4)$ with SIR $50 \mathrm{mg}$ q4w and $100 \mathrm{mg}$ q2w vs pbo $(61.4$ and $59.4 \%$ vs $43.9 \% ; P<0.001)$. FACIT-F scores $\geq$ normative values were reported by $33 \%$ of pts on SIR $50 \mathrm{mg}$ q $4 \mathrm{w}$ and $100 \mathrm{mg}$ q2w vs $22 \%$ on pbo. HAQ-DI scores at BL were 1.56, 1.50, and 1.52 with pbo, SIR 50mg q4w, and $100 \mathrm{mg}$ q2w, with clinically meaningful improvements $(\mathrm{MCID}=-0.22$ ) reported by 63.0 and $65.4 \%$ with SIR $50 \mathrm{mg} \mathrm{q4w}$ and $100 \mathrm{mg}$ q2w vs $46.9 \%$ with pbo $(P<0.001)$. HAQ-DI scores $\geq$ normative values were reported by numerically more pts receiving SIR $50 \mathrm{mg}$ q $4 \mathrm{w}$ (22\%) and $100 \mathrm{mg}$ q2w (21\%) vs pbo $(10 \%)$.

Table 1. Improvements in SF-36 Domain Scores at Wk 24 (all $P \leq 0.006$ )

\begin{tabular}{lccc}
\hline Domain & LSM change SIR 50mg q4w & LSM change SIR $100 \mathrm{mg}$ q2w & LSM change pbo \\
\hline Physical function & 10.48 & 12.39 & 2.85 \\
Role-physical & 14.88 & 16.04 & 7.96 \\
Bodily pain & 19.09 & 18.98 & 9.44 \\
General health & 8.90 & 7.53 & 3.57 \\
Vitality & 11.83 & 11.96 & 6.37 \\
Social function & 13.49 & 13.25 & 7.65 \\
Role-emotional & 12.50 & 11.74 & 6.54 \\
Mental health & 9.26 & 7.97 & 5.00 \\
\hline
\end{tabular}

LSM, least squares mean.

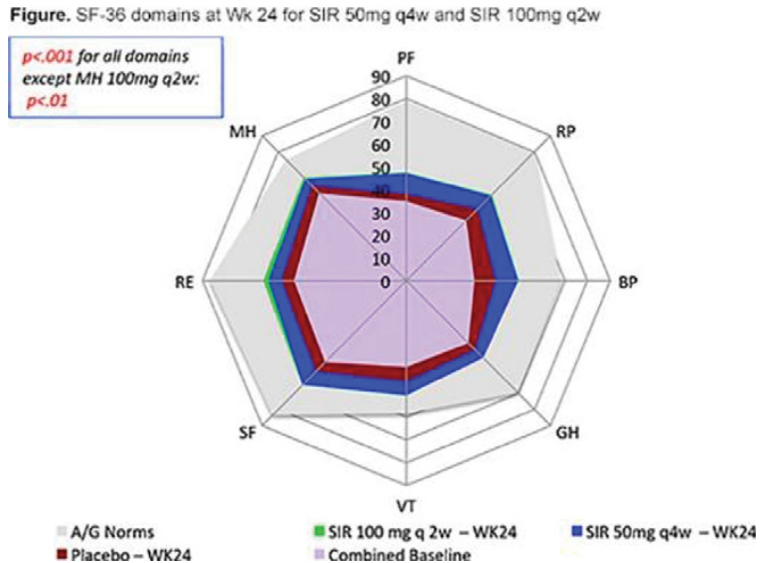

Conclusions: Through 24 wks, SIR treatment resulted in greater improvements in HRQoL than pbo that were clinically meaningful and met or exceeded normative values in DMARD-IR RA pts, with similar effects observed with both doses of SIR. Disclosure of Interest: V. Strand Consultant for: Abbvie, Amgen, AstraZeneca, Biogenldec, Boehringer Ingelheim, Celltrion, Crescendo, Genentech/Roche, GSK, 
Janssen, Lilly, Merck, Novartis, Pfizer, Regeneron, Samsung, Sanofi and UCB, K. McQuarrie Shareholder of: Janssen Research \& Development, LLC, Employee of: Janssen Research \& Development, LLC, N. Li Shareholder of: Janssen Research \& Development, LLC, Employee of: Janssen Research \& Development, LLC, R. Ganguly Shareholder of: GlaxoSmithKline, Employee of: GlaxoSmithKline DOI: 10.1136/annrheumdis-2017-eular.3917

\section{FRI0247 MEDIAN TIME TO LOW DISEASE ACTIVITY IS SHORTER IN TOCILIZUMAB COMBINATION THERAPY WITH CSDMARDS AS COMPARED TO MONOTHERAPY IN PATIENTS WITH ACTIVE RHEUMATOID ARTHRITIS AND INADEQUATE RESPONSES TO CSDMARDS AND/OR TNF INHIBITORS: SUBANALYSIS OF THE SWISS AND AUSTRIAN PATIENTS FROM THE ACT-SURE STUDY}

R. Mueller ${ }^{1}$, W. Graninger ${ }^{2}$, P. Sidiropoulos ${ }^{3}$, C. Goger ${ }^{4}$, J. von Kempis ${ }^{1}$. ${ }^{1}$ Division of Rheumatology, Kantonsspital St. Gallen, St. Gallen, Switzerland; ${ }^{2}$ Division of Rheumatology, Medical University of Graz, Graz, Australia; ${ }^{3} \mathrm{~F}$. Hoffmann-La Roche Ltd., South San Francisco, United States; ${ }^{4}$ Roche Austria $\mathrm{GmbH}$, Vienna, Austria

Background: To analyze efficacy and safety of tocilizumab in patients with rheumatoid arthritis (RA) and an inadequate response to conventional synthetic disease modifying anti-rheumatic drugs (csDMARDs) and/or tumour necrosis factor (TNF) inhibitors of the Swiss and Austrian patients from the ACT-SURE study.

\section{Objectives:}

Methods: Sub-analysis of RA patients from Switzerland and Austria, who participated in the international phase Illb, open-label, ACT-SURE study. Patients with an inadequate response to csDMARDs or TNF antagonists were included into the study receiving $8 \mathrm{mg} / \mathrm{kg}$ of IV tocilizumab every 4 weeks during a 24 week time period. Therapy with one or more csDMARDs could be continued as combination therapy with tocilizumab (Combo) or stopped, resulting in tocilizumab monotherapy (Mono), at the treating physician's discretion. These two patient groups were analyzed in separate and compared.

Results: Overall, 107 (22 on Mono vs 85 on Combo and) patients were treated with tocilizumab. The percentage of patients with at least one adverse event was significantly lower in the tocilizumab combination (58.8\%) as compared to the monotherapy group (81.8\%, $\mathrm{p}=0.0458)$. No differences in ACR20/50/70/90 response rates were observed between both treatment groups at week 24 (Mono: $63.6 \%, 40.9 \%, 22.7 \%$, and $18.2 \%$ vs. Combo: $61.2 \%, 43.5 \%, 25.9 \%$, and $10.6 \%$ ). The median time to low disease activity (LDA) was significantly shorter in patients treated with tocilizumab combination therapy Mono: 9.1, Combo 7.9 weeks, Log Rank $\mathrm{p}=0.038$ )

Conclusions: In this post hoc regional sub-analysis of the ACT-SURE study no differences for disease activity were found comparing the two patient groups at week 24. However, median time to LDA was statistically shorter in patients treated with tocilizumab combination therapy as compared to tocilizumab monotherapy. Consequently, adding tocilizumab to csDMARD therapy rather than changing to tocilizumab monotherapy may be, in our opinion, the safest strategy to reach maximum effect in RA patients with active disease despite treatment with CSDMARD. csDMARDs can be withdrawn either immediately due to adverse events or after at least low disease activity has been reached.

Disclosure of Interest: None declared

DOI: 10.1136/annrheumdis-2017-eular.5903

\section{FRI0248 INCIDENCE OF MELANOMA IN PATIENTS WITH RHEUMATOID ARTHRITIS TREATED WITH TOCILIZUMAB}

S. Gale ${ }^{1}$, J. Wang ${ }^{2}$, J.M. Nebesky ${ }^{3}$, A.T. Linke ${ }^{1}$, E. Berber ${ }^{1} .{ }^{1}$ Genentech, South San Francisco, CA, United States; ${ }^{2}$ Roche Products, Welwyn Garden City, United Kingdom; ${ }^{3}$ F. Hoffmann-La Roche, Basel, Switzerland

Background: There have been conflicting reports whether patients with rheumatoid arthritis (RA) receiving conventional or biologic immunosuppressive therapies are at increased risk of specific malignancies. Melanoma is an aggressive malignancy with risk factors including sex, age, fair skin and elevated cumulative UV exposure. Interleukin-6 (IL-6) has a role in pro- and antitumorigenic pathways. Whether tocilizumab (TCZ), a biologic that alters IL-6 signaling, increases the risk of melanoma in patients with RA is unclear.

Objectives: This age- and sex-adjusted standardized incidence ratio (SIR) analysis compared the observed reports of melanoma in patients with RA treated with TCZ in clinical trial and postmarketing settings with the expected number of cases across geographic regions.

Methods: SIRs for melanoma were calculated from the TCZ clinical trials allexposure population. Postmarketing rates were estimated from the TCZ Global Safety Database population. Both databases were searched cumulatively from 11 April 2005 to 10 October 2015. For clinical trials, observed reports of melanoma in patients with RA treated with TCZ were compared with expected number of cases in the general population based on the 2012 US Surveillance, Epidemiology, and End Results using an age- and sex-adjusted SIR. Postmarketing regional SIRs were calculated based on the estimated commercial exposure in each region and the incidence of melanoma as reported by Globocan by age and sex (2012).
Crude postmarketing rates were age- and sex-adjusted according to the clinical trial demographic profile to estimate the expected number of cases of melanoma in each region.

Results: In the clinical trial setting, 4 qualifying cases of melanoma were identified among 7093 patients with RA treated with TCZ (20,828 PY of exposure). The SIR estimate $(0.71$ [95\% Cl, 0.19-1.81]) for melanoma incidence in patients with RA treated with TCZ in clinical trials was comparable to that in the general population (Table 1). In the postmarketing setting, the number of observed reports of melanoma was comparable to the expected number of cases in Europe and Japan and fewer than expected in North America (Table 2). The exception is Australia, where SIR estimates indicated more than the expected number of cases in patients with RA receiving TCZ in Australia compared with the general population in that region (SIR 3.71 [95\% Cl: $2.16,5.93]$ )

Table 1. Incidence of melanoma in patients with RA from TCZ clinical trials, stratified by sex

\begin{tabular}{lcccc}
\hline Sex & $\begin{array}{c}\text { Observed } \\
\text { cases }^{\mathbf{a}}\end{array}$ & $\begin{array}{c}\text { Exposure } \\
\text { (PY) }\end{array}$ & $\begin{array}{c}\text { Expected } \\
\text { cases }^{\mathbf{b}}\end{array}$ & SIR $(95 \%$ CI) \\
\hline Female & 3 & 17,047 & 4.01 & $0.75(0.15,2.19)$ \\
\hline Male & 1 & 3781 & 1.66 & $0.60(0.02,3.35)$ \\
\hline All & 4 & 20,828 & 5.65 & $0.71(0.19,1.81)$ \\
\hline
\end{tabular}

a The age range of patients in the study cases was 50-64.

b Expected cases are based on Surveillance, Epidemiology, and End Results 2012 age-standardized incidence rates.

Table 2. Incidence of melanoma in patients with RA from TCZ postmarketing reports, stratified by region

\begin{tabular}{|c|c|c|c|c|}
\hline Region & $\begin{array}{c}\text { Observed } \\
\text { cases }\end{array}$ & $\begin{array}{l}\text { Region-Specific } \\
\text { Exposure (PY) }\end{array}$ & $\begin{array}{c}\text { Expected } \\
\text { cases }^{\circ}\end{array}$ & SIR (95\% CI) \\
\hline Europe & 30 & 126,683 & 26.6 & $1.13(0.76,1.61)$ \\
\hline North America & 17 & 131,546 & 36.9 & $0.46(0.27,0.74)$ \\
\hline Japan & 2 & 121,732 & 1.5 & $1.38(0.17,4.98)$ \\
\hline Australia & 17 & 6,480 & 4.6 & $3.71(2.16,5.93)$ \\
\hline
\end{tabular}

Combined exposure from Europe, North America, Japan and Australia accounts for $86 \%$ of the total cumulative postmarketing exposure and for all cases of melanoma at the data lock point of 10 October 2015.

- Expected cases are based on region-specific incidence rates in the general population (Globocan 2012).

PY, patient years; SIR, standardized incidence ratio; TCZ, tocilizumab.

Conclusions: In clinical trials, no evidence was found to suggest there were more cases of melanoma than expected in patients with RA treated with TCZ compared with the general population. Consistent with this, no evidence was found to suggest that patients with RA treated with TCZ in Europe, North America or Japan had more cases of melanoma than expected compared with the general population in each region. In contrast, the estimated SIR of melanoma in patients with RA treated with TCZ in Australia indicated more than the expected number of cases in the general population. This finding is consistent with reports of elevated risk of melanoma in patients with RA in Australia (compared with the general population), where UV exposure is high and methotrexate is a common first-line therapy. ${ }^{1,2}$

References:

[1] Buchbinder et al. Arthritis Rheum. 2008.

[2] Buchbinder et al. BMC Musculoskelet Disord. 2015.

Acknowledgements: Funded by Roche/Genentech.

Disclosure of Interest: S. Gale Employee of: Genentech, J. Wang Employee of:

Roche, J. Nebesky Employee of: Roche, A. Linke Employee of: Genentech, E. Berber Employee of: Genentech

DOI: 10.1136/annrheumdis-2017-eular.1314

\section{FRI0249 CIRCULATING FOLLICULAR HELPER-LIKE T CELLS IN PATIENTS WITH RHEUMATOID ARTHRITIS TREATED WITH ABATACEPT}

S. Piantoni ${ }^{1}$, M. Scarsi ${ }^{2}$, F. Regola ${ }^{1}$, A. Tincani ${ }^{1}$, P. Airò ${ }^{1} .{ }^{1}$ Rheumatology and Clinical Immunology Unit, Spedali Civili and University of Brescia, Brescia

${ }^{2}$ Internal Medicine Unit, Esine-Vallecamonica Hospital, Esine, Italy

Background: Rheumatoid arthritis (RA) is characterized by synovial inflammation and, in most cases, by autoantibodies, including rheumatoid factor (RF) and anticyclic citrullinated peptide antigen (ACPA), whose presence is associated to a more severe disease. The capability of producing autoantibodies is acquired by $B$ cells with the "help" of specialized T lymphocytes, known as Follicular helper $\mathrm{T}(\mathrm{TFH})$ cells, in the germinal centers (GC) of secondary lymphoid tissues. TFH express the inducible co-stimulator (ICOS), and are characterized by a high expression of CXC-chemokine receptor 5 (CXCR5), which mediate their migration into the GC, where its ligand CXCL13 is expressed. Here, TFH promote the GC development and $\mathrm{B}$ cell maturation. These cells are reported to exist in greater quantities in the peripheral blood (circulating TFH-like cells) of RA patients.

Abatacept $(A B A)$ is a fusion protein, which through its CTLA4 portion can bind to CD80 and CD86 on antigen presenting cells, thereby inhibiting CD28 costimulation. Data from animal models and phenotypic analysis of circulating $T$ cells in RA suggest that ABA may act in the secondary lymphoid organ, and not directly on the synovium $(1,2)$. While experimental models show that ABA can block the generation of TFH (3), little is known on the effect of ABA on circulating TFH-like cells of RA patients (4).

Objectives: To analyze the effect of the blockade of costimulation performed by 